\title{
Avalanche hazard zoning in Iceland based on individual risk
}

\author{
Porsteinn ARNALDS, ${ }^{1} \mathrm{~K}_{\text {Ristján JÓNASSON, }}{ }^{2}$ Sven SIGURĐSSON ${ }^{2}$ \\ ${ }^{1}$ Icelandic Meteorological Office, Bústadavegi 9, IS-150 Reykjavík, Iceland \\ E-mail: steini@vedur.is \\ ${ }^{2}$ The University of Iceland, Suðurgötu, IS-101 Reykjavik, Iceland
}

\begin{abstract}
Avalanche hazard is a threat to many residential areas in Iceland. In 1995 two avalanche accidents, causing a total of 34 fatalities in areas thought to be safe, prompted research on avalanche hazard assessment. A new method was developed, and in 2000 a new regulation on avalanche hazard zoning was issued. The method and regulation are based on individual risk, or annual probability of death due to avalanches. The major components of the method are the estimation of avalanche frequency, run-out distribution and vulnerability. The frequency is estimated locally for each path under consideration, but the run-out distribution is based on data from many locations, employing the concept of transferring avalanches between slopes. Finally the vulnerability is estimated using data from the 1995 avalanches. Under the new regulation, new hazard maps have been prepared for six of the most vulnerable villages in Iceland. Hazard zones are delineated using risk levels of $0.2 \times 10^{-4}, 0.7 \times 10^{-4}$ and $2 \times 10^{-4} \mathrm{a}^{-1}$, with risk less than $0.2 \times 10^{-4} \mathrm{a}^{-1}$ considered acceptable. When explaining the new zoning to the public, a measure of annual individual risk that allows comparison with other risks in society has proven advantageous.
\end{abstract}

\section{INTRODUCTION}

Iceland is located in the North Atlantic Ocean in an area of high cyclone activity. The climate and the mountainous landscape cause frequent avalanches in many areas of the country. Björnsson (1980) describes the general avalanche situation in Iceland. Iceland was settled in the ninth century AD, and the avalanche chronicle dates back to 1118 , when an avalanche killed five people in western Iceland. Since 1851 a total of 307 persons have been killed by avalanche and landslide accidents. A total of 90 of these fatalities occurred in five accidents in small coastal villages where 12 or more people were killed in each accident (see Table 1). The location of the most important villages that are threatened by avalanches is shown in Figure 1.

There were relatively few avalanche accidents in Iceland during the mid-20th century, probably due to relatively favourable climate conditions. The accident in Neskaupstadur in 1974 prompted some work on avalanche prevention, and the first law on avalanche prevention and control was passed in 1985. Subsequently, avalanche hazard zoning was carried out for several of the hazard-prone villages. The

Table 1. Casualties in the largest avalanche accidents in Iceland

\begin{tabular}{lll}
\hline \multicolumn{1}{c}{ Date } & Avalanche & Number of casualties \\
\hline 18 February 1885 & Seyðisfjörður & 24 \\
18 February 1910 & Hnífsdalur (Ísafjörður) & 20 \\
20 December 1974 & Neskaupstaður & 12 \\
16 January 1995 & Súðavík & 14 \\
26 October 1995 & Flateyri & 20 \\
& & \\
\hline
\end{tabular}

fatalities due to the avalanches in Súðavík and Flateyri in 1995 occurred mostly within areas considered "safe" according to this hazard zoning, and this led to the realization that the hazard-zoning procedure had been inadequate. The legislation on avalanche hazard zoning and control was rewritten (the current law was passed in 1997)and more funding was made available for avalanche research. The Icelandic Meteorological Office (IMO) was made responsible for most aspects of avalanche work, including hazard zoning, emergency evacuations and consultation regarding the construction of defence structures (Magnússon, 1998).

Following the new law, a regulation on avalanche hazard zoning, based on individual risk, was issued in 2000 (Iceland: Ministry for the Environment, 2000). Although the zoning is based on risk, the expression "hazard zoning", not "risk zoning", is used to describe the process since this is

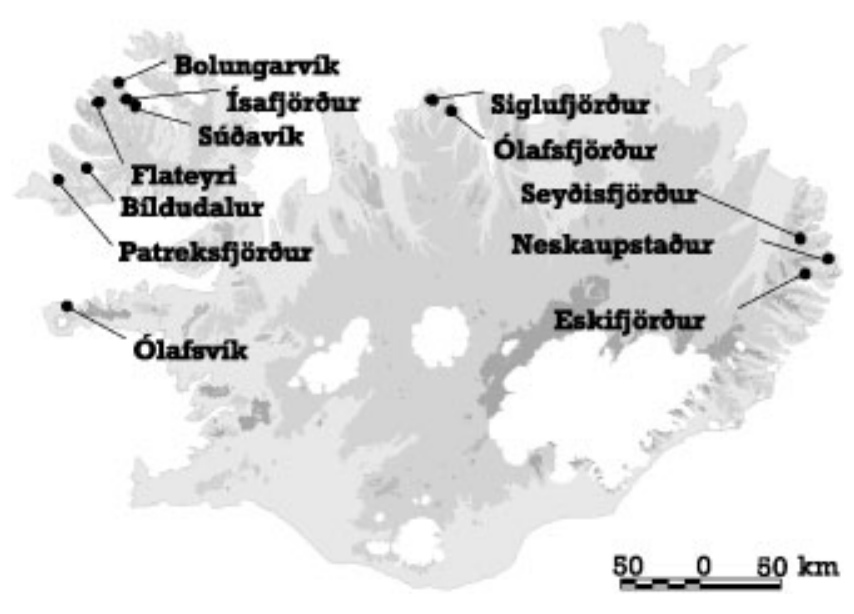

Fig. 1. Villages in Iceland threatened by avalanches. 
the traditional term. The hazard-zoning methodology used by the IMO was developed in collaboration with the University of Iceland (Jónasson and others, 1999). Based on these methods and the regulation, hazard zoning has been carried out for the most vulnerable villages in Iceland. In the following, the risk estimation method is outlined briefly and some results of the application of the method are summarized.

\section{HAZARD ZONING BASED ON INDIVIDUAL RISK}

In Switzerland and Austria the delineation of hazard zones is based on the estimated frequency of snow accumulation in starting areas of avalanches. A physical model is applied to calculate a corresponding run-out of avalanches. In Switzerland the limit of the hazard zones is located at the calculated run-out of an avalanche corresponding to snow accumulation in the starting area with a frequency $1 / 300 \mathrm{a}^{-1}$. In Norway the limit of the hazard zones is delineated where the frequency of avalanches is estimated to be $1 / 1000 \mathrm{a}^{-1}$.

Risk is the probability of a loss or injury. The loss can take several forms, such as economic loss, environmental damage or loss of lives. Models to evaluate risk usually deal with the risk as a product of factors. The World Meteorological Organization has proposed a risk model for weather-related hazards (WMO, 1999). The WMO model splits the risk in a hazard-prone area into hazard potential (hazard frequency and intensity) and vulnerability. If individual risk is to be estimated, the exposure of the individual to the hazard-prone area should be incorporated.

Although the economic loss due to avalanches in Iceland has been significant (Jóhannesson and Arnalds, 2001), the loss of lives is a dominant factor when considering the acceptability of the risk for the society. Furthermore, the avalanche risk is typically quite concentrated. It has been estimated that about 5000 people live in densely populated areas of Iceland where there is a considerable avalanche hazard. This estimate has been confirmed by the hazardzoning work. In the past few decades the average number of deaths due to avalanches in these areas has been about two per year. This indicates an average annual individual risk of about $4 \times 10^{-4}$ for people living in these areas. This is about five times the average annual individual risk due to traffic accidents in Iceland. The risk within the most endangered areas is of course much higher and thus unacceptable by any measure. After some deliberation, it was decided to base the Icelandic hazard-zoning regulation on individual risk. Reducing the individual risk would also reduce the aggregated risk to the society. Since only a small proportion of the population is exposed to the risk, an acceptable risk for the individuals will most likely also lead to acceptable risk for the society.

The Icelandic risk model can be split into four modules. The first two are the estimated frequency of avalanches in the slope above the area where the risk is to be estimated, and the run-out distribution of avalanches. These two components together encompass the hazard-frequency part of the general risk model. The vulnerability is represented by the probability of being killed if staying in a house that is hit by an avalanche, and the exposure is the proportion of the time that a person is expected to spend within the hazard-prone area.

Although the Icelandic risk model is the first method of this kind to be put into operation for avalanche hazard zoning, it should be noted that Keylock and others (1999) proposed a method for estimating individual avalanche risk based on run-out ratios, and Wilhelm (1997) analyzed the economic risk to traffic due to avalanches.

\section{Transferring avalanches}

In order to estimate the run-out distribution of avalanches in a particular avalanche path, it is usually necessary to include, implicitly or explicitly, information about run-out lengths in other avalanche paths. This is because the observed avalanches in each path are usually few, and a reliable statistical estimate cannot be obtained from the limited local observations alone. In order to facilitate an estimation of the run-out distribution, it is useful to transfer avalanches between slopes. It is possible to use both physical and topographical models for the transfer of avalanches between paths, and different statistical approaches can be used. Sigurðsson and others (1997) have attempted to classify the different types of transfer methods. The transfer method used in the Icelandic risk model is built around the PCM (Perla-Cheng-McClung) model of avalanche flow. The model is a physical model with two free parameters, the Coulomb friction parameter $\mu$ and the mass-to-drag parameter $M / D$ (Perla and others, 1980). However, the curvature term, $\kappa$, is separated from the $M / D$ term in our version of the model, i.e. the differential equation of the model is

$$
\frac{1}{2} \frac{\mathrm{d}}{\mathrm{d} s}\left(u^{2}\right)=g(\sin \theta-\mu \cos \theta)-\left(\mu \kappa+\frac{1}{M / D}\right) u^{2},
$$

where $u$ denotes the speed of the avalanche, $s$ the distance along the path, $\theta$ its slope, and $g$ the gravitational acceleration. In the numerical solution, a smoothing procedure is applied, so that the path has a continuous curvature rather than being composed of straight-line segments.

There is an infinite number of parameter pairs $(M / D, \mu)$ that will simulate the run-out length of a given avalanche in a given avalanche path. We refer to this set of pairs in the $(M / D, \mu)$ space as an isorunline. In order to find a single pair to simulate each avalanche, the choice of possible parameters is restricted to a line in the parameter space, called the parameter axis. It would be possible simply to fix the value of $\mu$ and thereby using $M / D$ as the single parameter to describe the size of the avalanche. Since there seems to be a difference in the effective value of the Coulomb friction when simulating large and small avalanches with the PCM model, this would not be realistic. It was therefore decided to vary both the $\mu$ and $M / D$ parameters as is done subjectively in traditional applications of the PCM model. The chosen axis has the equation

$$
\mu=0.6-0.0006 M / D \text {. }
$$

This, of course, is a simplification, but the resulting parameter values are within a range suggested by studies of the PCM model in other countries, and it has furthermore been shown that the final risk estimate is not very sensitive to the location of this axis (Jónasson and others, 1999). Figure 2 shows the isorunlines of several Icelandic avalanches together with the parameter axis. In order to transfer an avalanche from one path to another, i.e. to find a likely run-out distance in the second path, we find the parameter pair which is the interception between the axis and the isorunline of the avalanche for the first path. A simulation with the PCM model and this parameter pair is then run in the second path. 


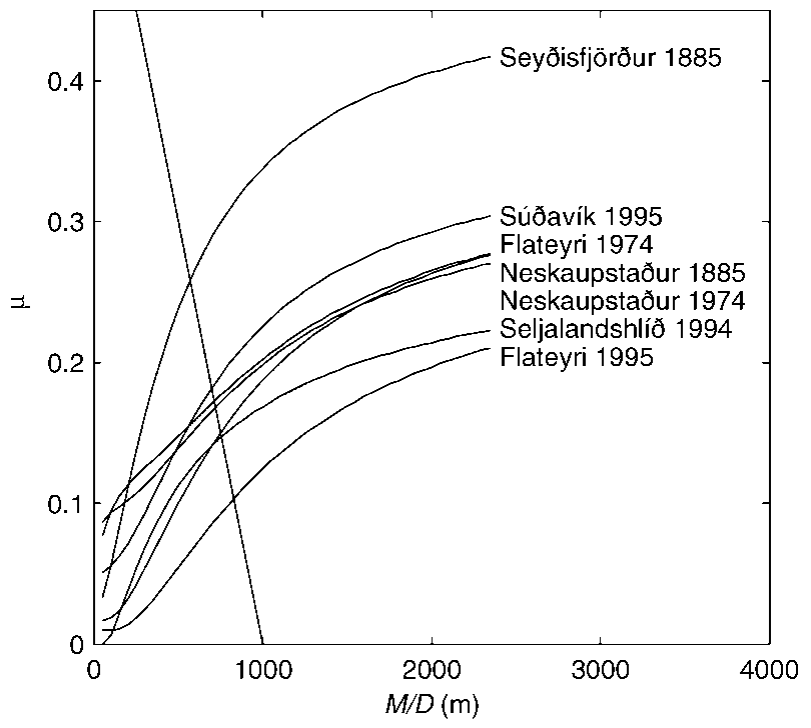

Fig. 2. Isorunlines of a few well-known Icelandic avalanches and the parameter axis.

\section{Run-out distribution}

The transfer of avalanches makes it possible to transfer avalanches in a dataset collected in many avalanche paths to a single path and subsequently estimate the distribution of run-out lengths. The dataset used for the Icelandic risk model consists of 196 avalanches that were recorded in 81 different paths. To estimate the run-out distribution in a given path, one could transfer all these avalanches to the path. To simplify the procedure and to avoid problems caused by unevenness in the run-out area, the approach adopted has been to estimate the distribution in a single artificial path and then transfer this globally estimated distribution to the path under consideration. The path used for the estimation is chosen to be typical for Icelandic avalanche slopes. It is parabola-shaped, $700 \mathrm{~m}$ high and $1600 \mathrm{~m}$ long. This slope is referred to as the standard path. The probability density of the run-out lengths is estimated using kernel estimation (e.g. Silverman, 1986). It should be noted that special consideration must be given to the dataset. There is reason to believe that in the dataset of 196 avalanches there are far too few small avalanches compared to longer ones. This bias is estimated using data from avalanche paths where records are more complete, and the probability distribution is corrected accordingly. The probability density of the run-out length, $r$, is referred to as $f(r)$.

The run-out length of avalanches in the standard path also gives a numerical measure for the run-out length. We call the run-out length in the standard path the run-out index. The unit of the run-out index is hectometres, so that an avalanche that reaches $1540 \mathrm{~m}$ in the standard path has a runout index of 15.4. The run-out index is also a useful concept in the absence of avalanches: we can, for example, say that a location where an avalanche with run-out index 13 would stop has run-out index 13. The run-out index concept can be extended to other types of transfer methods (Sigurðsson and others, 1997).

\section{Frequency}

If we estimate the frequency of avalanches at one location in an avalanche path, the run-out distribution will provide us with frequency estimates for other parts of the slope. Let us

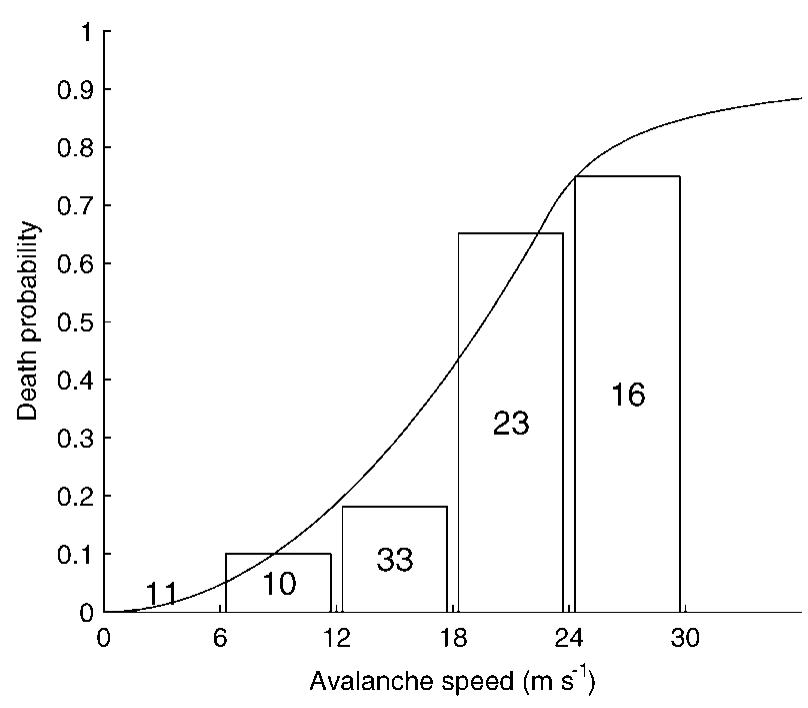

Fig. 3. The death rate in the avalanches at Flateyri and Súdavík as a function of avalanche speed. The numbers within the bars indicate the number of people that were at home for each speed interval. The curve is the fitted death probability (cf. Equation (5)).

assume that the frequency is estimated at run-out index $r_{0}$. For confined paths with complete records of avalanches for $T$ years and a total of $N_{r_{0}}$ avalanches with run-out greater than $r_{0}$, the estimated frequency at $r_{0}$ is simply

$$
F_{r_{0}}=\frac{N_{r_{0}}}{T} .
$$

The frequency at another location in the path, $r$, may then be estimated as

$$
F_{r}=F_{r_{0}} \int_{r}^{\infty} f(s) \mathrm{d} s / \int_{r_{0}}^{\infty} f(s) \mathrm{d} s .
$$

The lower the value of $r_{0}$ (i.e. the shorter the run-out), the more statistically reliable the estimate of the frequency becomes because $N_{r_{0}}$ will then be higher. However, avalanche records are more likely to be incomplete for low values of $r_{0}$. The completeness of the recordings also differs with time: the further back we go the more incomplete the records become. It can therefore be of advantage to estimate the frequency at several points in the path using different observation periods and compare the estimates.

The estimation of avalanche frequency can be adapted to unconfined slopes, taking into account the average width of avalanches and the total width of the slope. The statistical reliability of the frequency estimate for confined slopes can also be improved if it can be assumed that adjacent paths have similar characteristics and therefore the same frequency. The frequency is then estimated jointly for all the paths (Jónasson and others, 1999).

\section{Vulnerability}

The vulnerability of persons to avalanches will depend on several factors, such as whether they are inside a building, the strength of the building, and the size and speed of the avalanche. For the avalanches in Súðavík and Flateyri, information is available about how many people were staying in each of the houses that were hit and how many were killed. The speed of the avalanches when they hit the houses was estimated using the PCM model. Figure 3 shows the 
Table 2. Icelandic hazard-zone definitions

\begin{tabular}{lcll}
\hline Zone Lower level of local risk & $\begin{array}{l}\text { Upper level of local risk } \\
10^{-4} \mathrm{a}^{-1}\end{array}$ & Building restrictions \\
\hline C & 3 & 3 & $\begin{array}{l}\text { No new buildings, except for summer houses }{ }^{*} \text { and buildings where people are seldom } \\
\text { present }\end{array}$ \\
B & 1 & 1 & $\begin{array}{l}\text { Industrial buildings may be built without reinforcements. Homes have to be reinforced } \\
\text { and hospitals, schools, etc., can only be enlarged and have to be reinforced. The planning } \\
\text { of nousing areas is prohibited } \\
\text { Buildings where large gatherings are expected (e.g. schools, hospitals) have to be } \\
\text { reinforced }\end{array}$
\end{tabular}

*If the risk is less than $5 \times 10^{-4} \mathrm{a}^{-1}$.

proportion of people killed as a function of the calculated speed. As expected, the probability of being killed increases sharply as the speed increases. It is plausible to assume that this probability is approximately proportional to the kinetic energy of the avalanche. However, even at high speeds there seems to be some chance of surviving, and therefore a nonzero probability of survival is assumed in the limit of very high speeds. A continuously differentiable function has been fitted to the data using maximum likelihood estimation with the assumption that the probability of being killed is

$$
\mathrm{d}(v)= \begin{cases}k v^{2} & \text { if } v<v_{1} \\ c-\frac{a}{v-b} & \text { if } v>v_{1}\end{cases}
$$

The value of the terminal death probability is chosen to be $c=0.95$. This gives the estimates $v_{1}=23.0, k=0.00130$ and $a=1.151, b=18.61$. The,fitted function is shown in Figure 3. The data from Súðavík and Flateyri are considered to be representative for the consequences of avalanche impact on non-reinforced single family houses in Icelandic hazard areas.

\section{Exposure}

The exposure of persons to the avalanche hazard depends on their age and the type of building. For homes the exposure can be as high as $75 \%$, but in industrial buildings it will rarely be more than $30 \%$. The Icelandic hazard-zoning regulation, described below, adopts the concept local risk, which is defined as the annual probability of being killed for a person that stays all the time in a non-reinforced building. The local risk therefore omits the exposure. The actual risk may in each case be found given an appropriate assumption regarding the exposure.

\section{Risk model}

Given an estimate, $F_{r_{0}}$, of the avalanche frequency at a particular location, $r_{0}$, in an avalanche path, the individual risk at any location in the path may be readily obtained. The risk contribution of avalanches that exceed the given location, $r$, where the risk is to be estimated can be represented as an integral:

$$
\text { Risk at } r=F_{r_{0}} \int_{r}^{\infty} f(s) \mathrm{d}\left(v_{r}(s)\right) \mathrm{d} s / \int_{r_{0}}^{\infty} f(s) \mathrm{d} s,
$$

where $v_{r}(s)$ is the speed of an avalanche with run-out $s$ at location $r$. The purpose of the second integral is to normalize the run-out density function in the interval $\left[r_{0}, \infty\right)$.

\section{Acceptable risk}

When individual involuntary risk is $<10^{-6} \mathrm{a}^{-1}$, there is usually no reason for mitigation. When the annual risk is as high as $10^{-4}$ (approximately the risk of fatal traffic accidents in Iceland) there are, on the other hand, grounds for taking costly actions to reduce it. Thus an acceptable individual risk level will usually lie somewhere between these values. During formulation of the hazard-zoning regulation, the acceptable risk level was considered from several viewpoints, with the safety of children being the most important factor. The total annual mortality rate of children in Iceland is about $2 \times 10^{-4}$. It is clearly unacceptable that children living in areas threatened by avalanches have a much higher mortality rate than other children. It was considered acceptable that avalanche risk would contribute about $10 \%$ to the total risk of children, keeping in mind that other factors in the environment might be favourable, such as lower risk of traffic accidents. The acceptable risk for homes was thus set at $0.2 \times 10^{-4}$. Taking the exposure of $75 \%$, this gives an acceptable local risk of about $0.3 \times 10^{-4}$ if the person is not exposed to significant avalanche risk when not at home.

\section{APPLICATION OF RISK MODEL}

Parallel to the development of the risk model, it was applied to practical hazard-zoning projects and the results were compared to the results of other zoning methods. Since the regulation on avalanche hazard zoning was issued in 2000, hazard maps have been finalized for seven villages.

\section{Regulation}

The Icelandic regulation on hazard zoning is based on the local risk described above. The local risk of $0.3 \times 10^{-4} \mathrm{a}^{-1}$ is defined to be acceptable for residential areas, and three types of hazard zones are defined where the risk is progressively higher (see Table 2). The guidelines for the zoning and utilization of the hazard zones are tailored to attain the acceptable risk level in residences when the exposure and increased safety provided by reinforcements have been taken into account. For industrial buildings the guidelines probably correspond to a somewhat higher risk, but this may be justified by the absence of children.

\section{Comparison with other methods}

In 1997 a pilot project was carried out to delineate hazard zones in Seyðisfjörður, eastern Iceland, by several different methods. Three groups of experts proposed hazard maps. 


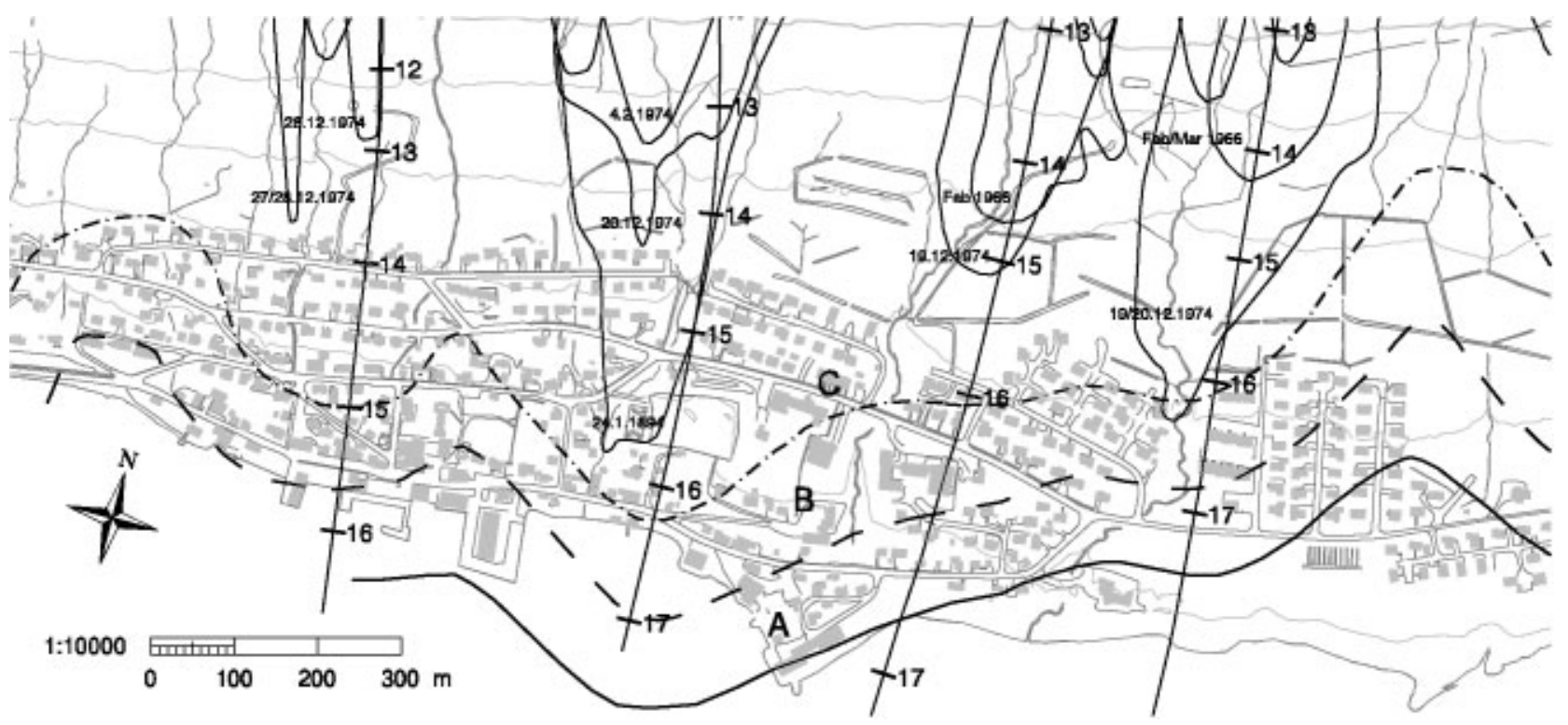

\begin{abstract}
Fig. 4. A hazard map for the eastern part of Neskaupstadur, scale 1:10 000. The solid line indicates the boundary of the category $A$ hazard zone, the dashed line the boundary of the B zone and the dashed-dotted line the boundary of the $C$ zone (cf. Table 2). Also shown are several of the longer recorded avalanches and their dates. The avalanches were released from the starting areas Urdarbotn, Drangagil, Nesgil and Bakkagil, counting from west to east. The area is to the east of the area where the accidents in 1974, that are mentioned in the text, took place. The lines along the slope are longitudinal sections used for the model computations. The numbers adjacent to the lines indicate run-out indices.
\end{abstract}

Firstly, an Icelandic group proposed a hazard map based on Icelandic methods and the (then proposed) regulation. Secondly, Norwegian experts made a hazard map according to Norwegian regulations and methods. Finally, an Austrian avalanche expert made a hazard map based on Austrian methods and regulation. Comparison of the results indicates that the Icelandic hazard-zoning regulation is somewhat stricter than those in effect in Norway and Austria. The acceptable risk level may be about three times lower in Iceland than in the other two countries (Arnalds, 2001).

\section{Completed hazard-zoning projects}

The first hazard map according to the regulation was finalized in May 2001, for the village of Neskaupstaður, eastern Iceland. Since then five other maps have been completed, for Siglufjörður, Seyðisfjörður, Eskifjörður, Ísafjörður and Bolungarvík, in that order. The majority of houses in urban areas of Iceland that are threatened by avalanches are located in these communities. Other types of rapid mass movements on steep slopes, such as slushflows, landslides and rockfalls, also threaten some of the areas. The Icelandic hazard-zoning regulation requires that these hazards should also be accounted for in the risk estimates. A comprehensive risk model has not been developed for these types of hazards, and a more subjective approach has therefore been necessary. The avalanche risk-estimation methods described above have been applied to some paths in all the areas where hazard maps have been finalized. It should, however, be noted that the dataset which forms the basis for the risk model consists mostly of avalanches from relatively high slopes (by Icelandic standards), i.e. $500-800 \mathrm{~m}$ high. On lower slopes it has been necessary to adapt the results of the risk model subjectively. Since the model is based on a one-dimensional avalanche model, it does not give an indication of the lateral extent of the hazard zones. For that purpose, the Austrian avalanche model SAMOS
(Snow Avalanche MOdelling and Simulation; Zwinger and others, 2003) has been run for most of the investigated avalanche paths. The results of the risk model have then been adjusted according to the results of the SAMOS simulations.

The hazard-zoning regulation defines a framework for the hazard-zoning process. The communities which are endangered by avalanches request a risk assessment from the Ministry for the Environment. The ministry appoints a hazard-zoning committee with two representatives from the ministry and two from the community. The hazard-zoning committee then requests a risk assessment from the IMO. The committee reviews the IMO's results and presents them to the public in the community. It has proved useful for representatives of the community to be involved in most of the hazard-zoning process and to take responsibility for the final result. As part of the procedure of introducing the hazard maps, reports relevant to the hazard zoning are published on a web page (www.vedur.is/snjoflod/haettumat).

\section{Case study}

Figure 4 shows a hazard map for the eastern part of Neskaupstaður. The mountain above the settlement rises to 700-900 $\mathrm{m}$ a.s.l. The mountainside is cut by many large gullies, which accumulate snow during northerly winds. Two avalanches, to the west of the area shown on the map, resulted in a tragic accident in 1974. The lower parts of four of the main avalanche paths (which total about seven) in the eastern part of Neskaupstaður are located in the area. The frequency of avalanches from the seven main gullies was considered to be comparable, except for Urðarbotn where the frequency is lower. The frequency was therefore estimated jointly for all the gullies except Urðarbotn, yielding an estimate of $F_{13}=0.05$, i.e. five avalanches per century from each gully with run-out beyond run-out index 13 . The frequency from Urðarbotn was considered to be five times 
lower, due to the size, shape and location of the starting areas. Given the frequency estimate, Equation (6) is used to calculate the risk by numerical integration. The hazard lines directly below the gullies represent risk calculations with the Icelandic risk model using the frequency estimates. The shape of the hazard lines is otherwise based on the results of SAMOS simulations and on subjective judgment.

\section{GONGLUSION}

The results of the risk calculations indicate that the average probability of being killed if staying in a house in the Icelandic hazard zones that is hit by an avalanche is about $0.1-0.25$. Given the acceptable local risk of $0.3 \times 10^{-4} \mathrm{a}^{-1}$, this indicates an acceptable annual exceedance probability of avalanches in the range from $1 / 7500$ to $1 / 3000$. These are very low probabilities and can be difficult to communicate to the public. The use of individual risk has proved to be useful in this situation, since it makes it possible to compare the avalanche risk to other risks that people are more familiar with. In some cases, this has changed the risk perception of the public and increased their risk awareness.

One way of checking the validity of the risk estimate of the hazard maps is to aggregate the total risk in all seven villages, take the age of the villages into account, and compare the result with the actual number of fatalities in past avalanche accidents. A rough calculation of this type indicates that the risk has been somewhat overestimated on average. A possible explanation is that in an uncertain situation where the hazard zoning relies heavily on subjective judgment the experts tend to be conservative. However, we believe that where the risk model is directly applicable, i.e. in typical avalanche paths with recorded avalanches, the risk estimates are less biased.

Although the risk model leaves many gaps for the experts to fill in with their personal judgment, based on experience, it provides a framework for that judgment. It enables them to structure their decisions and provides them with a useful tool to formulate the final result.

\section{AGKNOWLEDGEMENTS}

L. Tracy created Figure 1, and H. P. Sigurðsson the map in Figure 4. We thank T. Jóhannesson, T. Jónsson and M. M. Magnússon for useful comments on the text.

\section{REFERENGES}

Arnalds, D. 2001. Tilraunahettumat fyrir Seyðı́sfjörð-Yfirlit norðurhliðar. Reykjavík, Veðurstofa Íslands. (Report 01008.)

Björnsson, H. 1980. Avalanche activity in Iceland, climatic conditions, and terrain features. F. Glaciol., 26(94), 13-23. (Erratum: 27(96), 1981, p. 367.)

Iceland: Ministry for the Environment. 2000. Regulation on hazard zoning due to snow-and landslides classification and utilization of hazard zones and preparation of provisional hazard zoning. Reykjavík, Ministry for the Environment. (Government regulation.)

Jóhannesson, T. and P. Arnalds. 2001. Accidents and economic damage due to snow avalanche and landslide in Iceland. Fökull, 50, 81-94.

Jónasson, K., S. Sigurðsson and P. Arnalds. 1999. Estimation of avalanche risk. Reykjavík, Veðurstofa Íslands. (Report No VI-R99001-UR01.)

Keylock, C. J., D. M. McClung and M. M. Magnússon. 1999. Avalanche risk mapping by simulation. F. Glaciol., 45(150), 303-314.

Magnússon, M.M. 1998. The buildup of the avalanche section of the Icelandic Meteorological Office. In ISSW'98. International Snow Science Workshop, 27 September-1 October 1998, Sunriver, Oregon. Proceedings. Seattle, WA, Washington State Department of Transportation, 132-139.

Perla, R., T. T. Cheng and D. M. McClung. 1980. A two-parameter model of snow-avalanche motion. f. Glaciol., 26(94), 197-207.

Sigurðsson, S., K. Jónasson and P. Arnalds. 1998. Transferring avalanches between paths. In Hestnes, E., ed. 25 Years of Snow Avalanche Research, Voss 12-16 May 1998. Proceedings. Oslo, Norwegian Geotechnical Institute, 259-263. (NGI Publication 203.)

Silverman, B.W. 1986. Density estimation for statistics and data analysis. Vol. 26. New York, Chapman and Hall. (Monographs on Statistics and Applied Probability.)

Wilhelm, C. 1997. Wirtschaftlichkeit im Lawinenschutz - Methodik und Erhebungen zur Beurteilung von Schutzmassnahmen mittels quantitativer Risikoanalyse und ökonomischer Bewertung. Davos, Swiss Federal Institute for Forest, Snow and Landscape Research.

World Meteorological Organization (WMO). 1999. Comprehensive risk assessment for natural hazards. Geneva, World Meteorological Organization. (WMO TD 955.) www.waterday2004.org/docs/TD955.pdf

Zwinger, T., A. Kluwick and P. Sampl. 2003. Simulation of dry-snow avalanche flow over natural terrain. In Hutter, K. and N. Kirchner, eds. Dynamic response of granular and porous materials under large and catastrophic deformations. Heidelberg, etc., Springer, 161-194. 